University of Nebraska - Lincoln

DigitalCommons@University of Nebraska - Lincoln

Faculty Publications: Department of Entomology

Entomology, Department of

2-11-2019

\title{
Association of age, sex, and pyrethroid resistance status on survival and cytochrome P450 gene expression in Aedes aegypti (L.)
}

Leslie C. Rault

University of Nebraska - Lincoln, Irault2@unl.edu

Scott T. O'Neal

University of Nebraska - Lincoln, soneal3@unl.edu

Ellis J. Johnson

University of Nebraska - Lincoln, ellis.johnson@huskers.unl.edu

Troy D. Anderson

University of Nebraska - Lincoln, tanderson44@unl.edu

Follow this and additional works at: https://digitalcommons.unl.edu/entomologyfacpub

Part of the Entomology Commons, and the Genetics and Genomics Commons

Rault, Leslie C.; O'Neal, Scott T.; Johnson, Ellis J.; and Anderson, Troy D., "Association of age, sex, and pyrethroid resistance status on survival and cytochrome P450 gene expression in Aedes aegypti (L.)" (2019). Faculty Publications: Department of Entomology. 820.

https://digitalcommons.unl.edu/entomologyfacpub/820

This Article is brought to you for free and open access by the Entomology, Department of at DigitalCommons@University of Nebraska - Lincoln. It has been accepted for inclusion in Faculty Publications: Department of Entomology by an authorized administrator of DigitalCommons@University of Nebraska - Lincoln. 


\title{
Association of age, sex, and pyrethroid resistance status on survival and cytochrome P450 gene expression in Aedes aegypti (L.)
}

\author{
Leslie C. Rault, Scott T. O'Neal, \\ Ellis J. Johnson, Troy D. Anderson \\ Department of Entomology, University of Nebraska-Lincoln, \\ 103 Entomology Hall, Lincoln, NE 68583, USA \\ Corresponding author - L.C. Rault, email Irault2@unl.edu
}

\begin{abstract}
Aedes aegypti is a vector of viruses that negatively impact human health. Insecticide resistance complicates mosquito control efforts, but understanding the mechanisms of resistance can help to improve management practices. This study examined different factors that could influence the interpretation of toxicity bioassays and gene expression studies in A. aegypti, including sex and age, in the context of resistance to pyrethroids. Bioassays using a pyrethroid-resistant strain, Puerto Rico (PR), and a pyrethroid-susceptible strain, Rockefeller (Rock), of $A$. aegypti were conducted with females and males of three age groups to determine differences in mortality induced by deltamethrin. Overall, strain was the only factor with a significant effect on the LD50. Enzyme assays showed that cytochrome P450 monooxygenase activity in PR was constitutively higher than in Rock, and that pretreatment with the cytochrome P450 inhibitor piperonyl butoxide (PBO) followed by a topical application of deltamethrin (LD25) significantly increased mortality in both strains. Evaluation of the expression levels of seven CYP9J genes previously reported to be
\end{abstract}

Published in Pesticide Biochemistry and Physiology 156 (2019), pp 96-104.

doi 10.1016/j.pestbp.2019.02.007

Copyright (c) 2019 Elsevier Inc. Used by permission.

Submitted 26 November 2018; revised 7 February 2019; accepted 10 February 2019;

published 11 February 2019 
involved in pyrethroid resistance revealed that CYP9J10, CYP9J19, and CYP9J28 were more highly expressed in PR than in Rock at all ages of females and males, indicating that they may be essential for resistance. The expression of CYP9J24, CYP9J26, CYP9J27, and CYP9J32 was higher in PR males compared to other groups, including PR females. Significant differences in expression between sexes and strains were also observed as a result of age.

Keywords: Aedes aegypti, Pyrethroid resistance, Deltamethrin, PBO, Cytochrome P450, Gene expression

\section{Introduction}

Aedes aegypti (L.) is a mosquito species with a worldwide distribution, mainly present in tropical to temperate regions, including the southeastern United States (Kraemer et al., 2015; Centers for Disease Control and Prevention, 2017). More than just a nuisance, $A$. aegypti is a vector of flaviviruses such as dengue, yellow fever, and Zika viruses (Kyle and Harris, 2008; Muktar et al., 2016), as well as alphaviruses such as chikungunya virus, which can also be transmitted by Aedes albopictus (Powers and Logue, 2007), all affecting human health. The recent outbreak of Zika in the U.S. and its reemergence and spread in the Pacific islands and Micronesia (Duffy et al., 2009; Musso et al., 2014), chikungunya cases on all continents except Antarctica since 2004 (Coffey et al., 2014), and the continuous propagation of yellow fever and dengue worldwide, but particularly in Africa and South America (Tomori, 2004), stress the urgent need for effective control of the vector.

Historically, control of vector mosquito populations has been accomplished using organochlorine, organophosphate, carbamate, and pyrethroid insecticides, along with bacterial toxins from Bacillus thuringiensis var. israelensis (Bti) and insect growth regulators, which have been used as both larvicides and adulticides in water treatments, sprays, and treated fabrics, ultimately selecting for resistance to most modes of action (Georghiou et al., 1987; Rodríguez et al., 2002; Kroeger et al., 2006; Ranson et al., 2010). Currently, pyrethroids are dominant in the control of $A$. aegypti due to their relative safety for humans in insecticide-treated mosquito nets, particularly alphacyano pyrethroids such as alpha-cypermethrin, cyfluthrin, deltamethrin, and lambda-cyhalothrin, as well as non-cyano pyrethroids such as etofenprox and permethrin (Zaim et al., 2000; Hougard et al., 2003; Manjarres-Suarez and Olivero-Verbel, 2013). However, widespread use 
of pyrethroids has resulted in high selection pressure that has driven field-evolved resistance to pyrethroids in A. aegypti populations (Ranson et al., 2010; Vontas et al., 2012; Smith et al., 2016).

Known mechanisms of resistance to multiple insecticide classes often involve increased activity of detoxification enzymes such as esterases, cytochrome P450s, and glutathione S-transferases (GSTs) (Lumjuan et al., 2005; Strode et al., 2008; Francis et al., 2017) and/or target site modifications, mainly in the sequence of acetylcholinesterase (Hemingway et al., 1989), the gamma-aminobutyric acid (GABA) receptor (Thompson et al., 1993), and the voltage-gated sodium channel (Brengues et al., 2003; Du et al., 2016). Although multiple nonsynonymous target site mutations were detected in strains of pyrethroidresistant $A$. aegypti from Puerto Rico, the Grand Cayman, Cuba, Thailand, French Guiana, Guadeloupe, New Caledonia, and Isla Mujeres (Mexico), these strains also exhibited high levels of cytochrome P450 gene expression (Strode et al., 2008; Bariami et al., 2012; Reid et al., 2014; Dusfour et al., 2015; Estep et al., 2017). This may be explained by the abundance of detoxification genes in the genome of $A$. aegypti (Strode et al., 2008), but also by the prominence of cytochrome P450mediated pyrethroid resistance in insects (Tomita and Scott, 1995; Ranasinghe and Hobbs, 1998; Yang et al., 2006; Komagata et al., 2010; Riveron et al., 2013).

It was demonstrated that certain cytochrome P450s, especially CYP9Js, were more highly expressed in diverse pyrethroid-resistant strains of $A$. aegypti. More specifically, it was shown that the genes CYP9J10, CYP9J19, CYP9J26, CYP9J27, and CYP9J28 were more highly expressed in two strains (Cayman and Cuba) of pyrethroid-resistant $A$. aegypti (Bariami et al., 2012). Stevenson et al. (2012) cloned and expressed CYP9J24 and CYP9J32, in addition to the other genes investigated by Bariami et al. (2012) that were all highly expressed in Isla Mujeres and Merida strains of $A$. aegypti, to determine their role in the metabolism of permethrin and deltamethrin. It was concluded that CYP9J24, CYP9J26, CYP9J28, and CYP9J32 are capable of metabolizing deltamethrin and permethrin. Moreover, in 2- to 5-days old females of the Puerto Rico strain, the cytochrome P450 inhibitor piperonyl butoxide (PBO) was tested in combination with permethrin and found to reduce permethrin resistance from 73 -fold to 15 -fold when compared to the susceptible Orlando strain. This result suggested a P450-mediated resistance to pyrethroids (Reid et al., 2014). CYP transcripts that 
are more highly expressed in Puerto Rico, as compared to the susceptible strain Orlando, coincided with previous findings (Estep et al., 2017). The pyrethroids permethrin, alpha-cypermethrin, and etofenprox were tested on these strains and Puerto Rico was resistant to all three pyrethroids in addition to a 19-fold resistance to DDT and 3.7fold resistance to indoxacarb. Overall, 26 CYP genes, including CYP9J9, CYP9J23, and CYP9J27, were expressed with a 2-fold or higher difference in Puerto Rico than Orlando.

The identification of resistance mechanisms and resistance monitoring require laboratory testing. The World Health Organization (WHO) states that the results of insecticide susceptibility tests can be affected by the sex, age, and physiological status of mosquitoes (World Health Organization, 2016). Males are considered more fragile and are not typically used for resistance monitoring due to high levels of control mortality. The most recent recommendation by the World Health Organization is to use adult females between 3 and 5 days old (World Health Organization, 2016), although it was previously recommended to use "young" mosquitoes between 1 and 3 days old (World Health Organization, 1998). Lines and Nassor (1991) established that resistance to DDT decreased with age in Anopheles gambiae, and Chouaibou et al. (2012) demonstrated that susceptibility to deltamethrin, permethrin, malathion, and propoxur increased with age. However, these recommendations and studies focused on Anopheles mosquitoes and examined a wide range of ages, up to 12 to 14 days old adult females. Toxicity bioassays using female Aedes mosquitoes of different ages exposed to pyrethroid-impregnated fabric revealed that 3-day old mosquitoes were knocked down more slowly than 14-day old mosquitoes, regardless of the strain or species, confirming that age could play a role in susceptibility (Rajatileka et al., 2011). The commonly used age groups vary in a narrower range, including 1 to 3 days old (Flores et al., 2013), 2 or 3 to 5 days old (Hougard et al., 2003; McAllister et al., 2012; Ngoagouni et al., 2016), and 5 to 7 days old (Pridgeon et al., 2008). This heterogeneity emphasizes the lack of standardization in laboratory testing for $A$. aegypti, which could influence the conclusions from bioassays and gene expression studies and lead to incorrect assessments of susceptibility and resistance characteristics of a population.

An understanding of control failures and of the underlying resistance mechanisms can lead to the improvement of control strategies 
by using insecticides that do not share common resistance mechanisms. Mosquito responses to insecticide exposure as measured by mortality, enzyme activity, and gene expression could vary with age, since different age ranges may have a different susceptibility to insecticides. Sex is also an important factor, as resistant males propagate their resistance alleles in the population. This study examined different factors that could influence the interpretation of toxicity bioassays and gene expression studies in A. aegypti, including sex and age, in the context of resistance to pyrethroids. Furthermore, this study investigated the influence that these factors have on mortality and enzyme activity following pyrethroid exposure, and changes in gene expression. The goals of this study are to assess the legitimacy of using different age groups in bioassays and to identify candidate genes in pyrethroid resistance exhibited by the Puerto Rico strain as compared to the susceptible Rockefeller strain of $A$. aegypti.

\section{Materials and methods}

\subsection{Mosquitoes}

Two strains of mosquitoes were used in this study: (1) a susceptible laboratory population, Rockefeller (Rock), established in 1937 (obtained through BEI Resources, NIAID, NIH: Aedes aegypti, Strain ROCK, MRA-734, contributed by David W. Severson), and (2) a pyrethroid-resistant strain, Puerto Rico (PR), collected from San Juan, Puerto Rico and maintained in the laboratory under selection pressure since 2012 (provided by Centers for Disease Control and Prevention (CDC) for distribution by BEI Resources, NIAID, NIH: Aedes aegypti, Strain Puerto Rico, Eggs, NR-48830). Eggs from these strains were reared to adulthood separately. Adult mosquitoes were maintained at $27^{\circ} \mathrm{C}$ and 70 $80 \%$ relative humidity with a photoperiod of $12: 12$ (light: dark). Adults were kept in screened cages and provided with $10 \%$ sucrose solution ad libitum. In order to produce eggs, female mosquitoes were provided a blood meal of defibrinated sheep blood (Remel Incorporated, San Diego, CA) using an artificial glass mosquito feeder (Chemglass Life Sciences LLC, Vineland, NJ) and allowed to oviposit on seed paper (Anchor Paper Company, Saint Paul, MN). Eggs were hatched, and larvae were reared in plastic containers partially filled with distilled 
water at approximately $25^{\circ} \mathrm{C}$. Larvae were fed ground fish food flakes (TetraMin, Melle, Germany). Pupae were transferred to a $100 \mathrm{~mL}$ beaker containing distilled water and were placed in an adult cage for emergence. Mosquitoes were aspirated and transferred to a new cage within $24 \mathrm{~h}$ of emergence in order to maintain age-matched cohorts of each strain. Mosquitoes were anesthetized on ice and females and males were separated for experiments. Females and males of three age ranges were collected for toxicity bioassays, RNA extraction, and subsequent gene expression analysis: 1 to 3 days old, 3 to 5 days old, and 5 to 7 days old. Triplicates of 10 mosquitoes were tested and subsequently flash frozen in liquid nitrogen and stored at $-80^{\circ} \mathrm{C}$ until microsome preparation or RNA extraction.

\subsection{Toxicity bioassays}

Mosquitoes were anesthetized on ice and received a treatment depending on age, sex, and strain. The average weight of each category (delimited by age, sex, and strain) was determined by weighing 3 groups (triplicates) of 10 mosquitoes. The obtained weights were analyzed in a three-way ANOVA with Tukey's multiple comparison test.

Each condition consisted of 3 replicates of 10 mosquitoes. Each mosquito received a topical application of $0.2 \mu \mathrm{L}$ of either acetone (Sigma-Aldrich, Saint Louis, MO) as a control treatment, or technical grade deltamethrin (Chem Service Inc., PA), diluted in acetone, on the pronotum. Mosquitoes from the Rock strain (females and males) were treated with one of the following concentrations of deltamethrin: $0.0015,0.005,0.015,0.05$, or $0.15 \mathrm{ng} / \mu \mathrm{L}$. Mosquitoes from the PR strain (females and males) were treated with one of the following concentrations of deltamethrin: $0.15,0.5,1.5,5$, or $15 \mathrm{ng} / \mu \mathrm{L}$. The dose of deltamethrin treatments was calculated by multiplying the total volume applied to each mosquito $(0.2 \mu \mathrm{L})$ by the concentration of the stock solution, then dividing the product by the average body weight of each mosquito group (depending on age and sex). Following topical application of acetone or deltamethrin, mosquitoes were transferred into soup cups covered by mesh and sealed with a rubber band to prevent escape and were supplied with cotton balls soaked in $10 \%$ sucrose. Mortality was determined $24 \mathrm{~h}$ after treatment as defined by the $(D C)$, which includes any mosquito that has been 'immobilized' and can no longer stand. Abbott's correction (Abbott, 1925) 
was utilized to account for mosquito mortality in the control groups, and if control mortality exceeded $20 \%$, data from that test group were not used. The dose-response curve was obtained with a nonlinear regression to calculate the $\mathrm{LD}_{50}$ values and confidence intervals for each group and a linear regression to calculate the slope of the regression. Differences in $\mathrm{LD}_{50}$ values were assessed based on a three-way ANOVA and Tukey's multiple comparison test. All statistical tests were carried out at a significance level of 0.05 . All statistical analyses for toxicity bioassays and enzyme assays were performed with GraphPad Prism version 7.00 for Windows (GraphPad Software, La Jolla California USA, www.graphpad. com).

\subsection{Synergist bioassays}

\subsubsection{Cytochrome $P 450$ monooxygenase activity}

Microsomal cytochrome P450 monooxygenase (P450) activity was measured and compared in 3 to 5 days old females and males of both the Rock and PR strains in order to verify that PBO (Chem Service Inc., PA) had the expected effect on cytochrome P450 activity. Each group was topically exposed to $0.2 \mu \mathrm{L}$ of either acetone (control) or $100 \mathrm{mM}$ PBO.

Per sample, 10 mosquitoes were flash frozen in an Eppendorf tube and stored at $-80^{\circ} \mathrm{C}$ until microsome preparation. Microsomes were isolated to maximize the precision of P450 activity readings using the commercial microsome isolation kit produced by Abcam (Cambridge, MA), following the manufacturer instructions. A protein assay, adapted from Smith et al. (1985) was performed to standardize P450 activity in relation to the amount of total protein contained in each sample, based on an umbelliferone standard curve. Concomitantly, the microsome preparations were used in a fluorometric assay to measure P450 activity by 7 -ethoxycoumarin $O$-deethylation resulting in fluorescent 7-hydroxycoumarin (Weber, 1972; Desousa et al., 1995; Stumpf and Nauen, 2001; Anderson and Zhu, 2004). Each sample type was replicated 3 times (biological replicates) and technical replicates were pipetted in triplicates. Fluorescence was measured with a SpectraMax i3x microplate fluorescence reader (Molecular Devices, San Jose, CA) at 465 $\mathrm{nm}$ while exciting at $390 \mathrm{~nm}$, using black Costar UV transparent 96well microplates (Corning Inc., Corning, NY). Readings were collected with the software SoftMax Pro 7.0 (Molecular Devices, San Jose, CA). 
The plate readings obtained were converted to relative fluorescence units (RFU) and scaled with the total protein content of each sample (RFU/mg protein). Data were analyzed by comparing strain and treatment differences for the two sexes using a two-way ANOVA followed by Tukey's multiple comparisons test. All statistical tests were carried out at a significance level of $P \leq .05$.

\subsubsection{Bioassay with $P B O$}

Female and male mosquitoes of the Rock and PR strains were exposed by age groups to deltamethrin in order to evaluate differences in mortality ( $C D C$ definition). A dose of PBO was determined based on solubility limits and mosquito weight. The pre-exposure time of PBO was determined by a preliminary experiment showing reduced cytochrome P450 activity in mosquitoes after $4 \mathrm{~h}$. Female mosquitoes received $0.2 \mu \mathrm{L}$ of acetone (control) or $0.2 \mu \mathrm{L}$ of $100 \mathrm{mM}(20 \mathrm{mM}$ ) of PBO prepared in acetone. Males received $0.2 \mu \mathrm{L}$ of acetone (control) or 0.2 $\mu \mathrm{L}$ of $35.7 \mathrm{mM}(7.14 \mathrm{mM}$ ) of PBO (proportioned to account for the weight difference between females and males). For each age group, each sex, and each strain, at $4 \mathrm{~h}$ after PBO treatment, triplicates of 10 mosquitoes were anesthetized on ice and topically treated with either $0.2 \mu \mathrm{L}$ of acetone as a control or $0.2 \mu \mathrm{L}$ of deltamethrin at the calculated $\mathrm{LD}_{25}$ values, ROCK females received $0.001 \mathrm{ng}$ and males 0.00003 $\mathrm{ng}$ of deltamethrin, PR females received $0.1 \mathrm{ng}$ and PR males $0.04 \mathrm{ng}$. Following topical application of acetone or deltamethrin, mosquitoes were transferred into soup cups covered by mesh. Mortality was recorded $24 \mathrm{~h}$ after deltamethrin treatment. Mortality differences between treatments and groups were analyzed by strain in a two-way ANOVA followed by Tukey's multiple comparisons test. Age and sex data were merged within a treatment, if no difference was found in the previous analysis, and mortality percentages per treatment and per strain were analyzed with a one-way ANOVA followed by a Sidak's multiple comparisons test and comparisons exhibiting $P \leq .05$ were considered significant.

\subsection{Gene expression}

\subsubsection{RNA extraction and $C D N A$ synthesis}

The RNA extraction area and materials were treated with RNasezap ${ }^{\circledR}$ (Ambion Inc., Foster City, CA). RNA extraction was performed 
using Tri Reagent RT (Molecular Research Center, Inc., Cincinnati, OH) and $1 \mu \mathrm{g}$ of RNA per $20 \mu \mathrm{L}$ reaction volume was reverse transcribed using the iScript cDNA reverse transcription kit following manufacturer indications (Biorad, Hercules, CA). The resulting cDNA was diluted 2fold to accommodate the volumes of the reaction.

\subsubsection{Quantitative-reverse transcriptase $P C R$}

Primer pairs for the quantitative reverse transcriptase polymerase chain reaction (qRT-PCR) were either designed using the online software Primer3 (Rozen and Skaletsky, 2000) or were A. aegypti specific primer pairs (Table 1). All primers were synthesized by Sigma-Aldrich (Saint Louis, MO).

The qRT-PCR experiments were performed using a Biorad CFX Connect Real-Time System with iTaq Universal SYBR ${ }^{\circledR}$ Green Supermix (Biorad). The PCR cycle protocol program consisted of an initial step of $3 \mathrm{~min}$ at $95^{\circ} \mathrm{C}$ for denaturation, followed by 40 cycles of the following steps: $10 \mathrm{~s}$ at $95^{\circ} \mathrm{C}$ for denaturation, $30 \mathrm{~s}$ at $59{ }^{\circ} \mathrm{C}$ for primer annealing, and $30 \mathrm{~s}$ at $72{ }^{\circ} \mathrm{C}$ for primer extension. After a final step of $72{ }^{\circ} \mathrm{C}$ for $5 \mathrm{~min}$, a melting curve was taken from $65^{\circ} \mathrm{C}$ to $95^{\circ} \mathrm{C}$ by increments of $0.5^{\circ} \mathrm{C}$ for $5 \mathrm{~s}$. All reactions consisted of $2 \mu \mathrm{L}$ of cDNA, $0.5 \mu \mathrm{L}$ of each primer at $10 \mu \mathrm{M}, 5 \mu \mathrm{L}$ of SYBR ${ }^{\circledR}$ green and $2 \mu \mathrm{L}$ of water, for a total volume of $10 \mu \mathrm{L}$. Each condition was repeated in technical triplicates.

Table 1. List of primers, the genes they are associated with, product size, efficiency, and origin.

\begin{tabular}{|c|c|c|c|c|c|}
\hline Gene & Forward primer & Reverse primer & $\begin{array}{l}\text { Product } \\
\text { length }\end{array}$ & Efficiency & Origin \\
\hline Actin & CGTTCGTGACATCAAGGAAA & GAACGATGGCTGGAAGAGAG & 175 bp & $98.8 \%$ & Dzaki et al. (2017) \\
\hline RPS17 & AAGAAGTGGCCATCATTCCA & GGTCTCCGGGTCGACTTC & 200 bp & $95 \%$ & Dzaki et al. (2017) \\
\hline CYP9J10 & ATTCGGTGTTGGTGAAAGTTCTGT & CATGTCGTTGCGCATTATCCC & $160 \mathrm{bp}$ & $106.7 \%$ & Bariami et al. (2012) \\
\hline CYP9J19 & AGTACCTCTACTTTCTGGC & GAAAAGCGTAGTACAACTCGT & 129 bp & $103.7 \%$ & Bariami et al. (2012) \\
\hline CYP9J24 & GATGACGGACGTGGAAATGG & TCTGGATCTCGTCGTACAGC & 143 bp & $106.1 \%$ & $\begin{array}{l}\text { Sequence from } \\
\text { Stevenson et al. (2012) } \\
\text { but custom designed }\end{array}$ \\
\hline CYP9J26 & ССTCTCCTGCTGCGAAAGGTC & CGTCTCGAACATCCCGAAAACTTT & $93 \mathrm{bp}$ & $101.3 \%$ & Bariami et al. (2012) \\
\hline CYP9J27 & GTTGTTCGATGAAGAAAGTGCTGA & GGAGGTCTTCGCCTTCTTTACAT & $100 \mathrm{bp}$ & $102.7 \%$ & Bariami et al. (2012) \\
\hline CYP9J28 & CAATGACGAAAACAAGCGGAAC & GGCCCAAATTAGTGAACCCCT & 222 bp & $99.6 \%$ & Bariami et al. (2012) \\
\hline CYP9J32 & CTGCAAGTCGAATCGCTCAA & GATCCCATGAGTCTCCCGAG & 222 bp & $100.9 \%$ & $\begin{array}{l}\text { Sequence from } \\
\text { Stevenson et al. (2012) } \\
\text { but custom designed }\end{array}$ \\
\hline
\end{tabular}


The statistical analysis of the qRT-PCR results was performed using the R (R Core Team, 2013) package MCMC.qpcr (Matz et al., 2013). This method uses a generalized linear mixed model (GLMM), allowing information from all genes to be considered to estimate fixed and random effects. GLMM permits the analysis of complex designs by an ANOVA-type analysis, contrary to more traditional $\Delta \Delta C t$ methods working by pairwise comparisons. The model also considers primer efficiencies and allows the calculation of molecule counts from $\mathrm{C} t$ values for all conditions. Prior to analysis, outliers of technical replicates were removed after visualization of the melt curve and amplification curve.

All transcripts of interest and two housekeeping genes were analyzed. The housekeeping genes selected for the analysis were $\beta$-actin and ribosomal protein S17 (RPS17) (Dzaki et al., 2017), however, these genes were not specified as "control" genes since no assumption was made about their stability, which is one of the features of the package used. The effect of age, sex, and strain on the expression of the selected genes was measured. $P$-values were corrected for multiple tests by applying the method of Benjamini and Hochberg (1995) with a false discovery rate of $5 \%$.

\section{Results}

\subsection{Toxicity bioassays}

Weight was significantly different between females and males within each strain ( $\mathrm{F}=586.1, \mathrm{df}=1, P<.0001)$. On average, Rock females were 2.21-fold heavier than males and PR females were 1.98- fold heavier than males, which results in a 2.08-fold weight difference between sexes across strains. There was also a significant effect of strain on weight $(\mathrm{F}=21.78, \mathrm{df}=1, P<.0001)$ and a significant interaction between strain and sex $(F=15.74, d f=1, P=.0001)$. $P R$ females between 1 and 5 days old were also significantly heavier than Rock females $(P<.0001$ at 1 to 3 days old, $P=.0476$ at 3 to 5 days old). The calculated $\mathrm{LD}_{50}$ values for deltamethrin are shown in Table 2. The ANOVA revealed differences between strains only $(\mathrm{F}=76.4, \mathrm{df}=1, P<.0001)$. Overall, PR exhibited $L_{50}$ values approximately 75 -fold greater than Rock. 
Table 2. $L D_{50}$ values adapted to the weight of mosquito groups, in $\mathrm{pg} / \mathrm{mg}$, and related values calculated for Rockefeller and Puerto Rico strains of the mosquito species Aedes aegypti after exposure to a range of deltamethrin concentrations.

\begin{tabular}{|c|c|c|c|c|c|c|c|c|c|c|}
\hline \multirow[b]{2}{*}{$\begin{array}{l}\text { Age group } \\
\text { in days post } \\
\text { emergence }\end{array}$} & \multicolumn{5}{|l|}{ Males } & \multicolumn{5}{|c|}{ Females } \\
\hline & $\begin{array}{l}L D_{50} \text { in } \\
\mathrm{pg} / \mathrm{mg}\end{array}$ & 95\% C.I. & $R^{2}$ & Slope & $N$ & $\begin{array}{l}L D_{50} \text { in } \\
\mathrm{pg} / \mathrm{mg}\end{array}$ & 95\% C.I. & $R^{2}$ & Slope & $N$ \\
\hline \multicolumn{11}{|l|}{ Rockefeller } \\
\hline 1 to 3 & 1.6 & 0.66 to 3.7 & 0.89 & $57.87 \pm 15.37$ & 30 & 4.281 & 2.6 to 7.41 & 0.974 & $45.93 \pm 7.13$ & 30 \\
\hline 3 to 5 & 3.28 & 1.17 to 9.58 & 0.87 & $51.33 \pm 7.33$ & 30 & 2.603 & 1.14 to 6.4 & 0.918 & $46.01 \pm 6.72$ & 30 \\
\hline 5 to 7 & 0.98 & 0.27 to 2.68 & 0.73 & $34 \pm 7.34$ & 60 & 2.792 & 1.73 to 4.63 & 0.936 & $51.03 \pm 6.82$ & 60 \\
\hline \multicolumn{11}{|l|}{ Puerto Rico } \\
\hline 1 to 3 & 153.9 & 63.31 to 355.5 & 0.89 & $57.87 \pm 15.37$ & 30 & 314.2 & 191 to 544.2 & 0.974 & $45.93 \pm 7.13$ & 30 \\
\hline 3 to 5 & 163.2 & 61.92 to 421.7 & 0.88 & $54.46 \pm 13.52$ & 30 & 204.9 & 109.5 to 397.3 & 0.946 & $56.71 \pm 9.85$ & 30 \\
\hline 5 to 7 & 164.7 & 55.95 to 460.1 & 0.85 & $50.54 \pm 13.54$ & 30 & 172 & 77.19 to 411.2 & 0.909 & $55.26 \pm 10.74$ & 30 \\
\hline
\end{tabular}

\subsection{Synergist bioassays}

\subsubsection{Cytochrome P450 monooxygenase activity}

The interaction between Strain-Sex and treatment factors was significant $(\mathrm{F}=15.25, \mathrm{df}=3, P<.0001)$. Cytochrome P450 activity in females and males was significantly higher in PR than in Rock individuals when comparing the control of each strain (acetone). PR females exhibited a lower cytochrome P450 activity than PR males (significant Strain-Sex effect, $\mathrm{F}=39.17, \mathrm{df}=3, P<.0001)$. The effect of treatment was also significant $(\mathrm{F}=195.3, \mathrm{df}=1, P<.0001)$, as cytochrome P450 activity decreased $50 \%$ in Rock males and between 70 and $80 \%$ in Rock females and PR females and males following treatment with $\mathrm{PBO}$ as compared to treatment with acetone (Fig. 1).

\subsubsection{Bioassay with $P B O$}

Mortality was significantly increased in both strains between the exposure to deltamethrin alone at the calculated $\mathrm{LD}_{25}$ and the exposure to deltamethrin at the $\mathrm{LD}_{25}$ after $\mathrm{PBO}$ pretreatment $(\mathrm{F}=1083, \mathrm{df}=3$, $P<.0001$ ) (Fig. 2). The mortality for Rock reached ca. 93\%, while it increased to ca. $70 \%$ for PR. There was no significant difference in mortality between the age groups or sexes. 


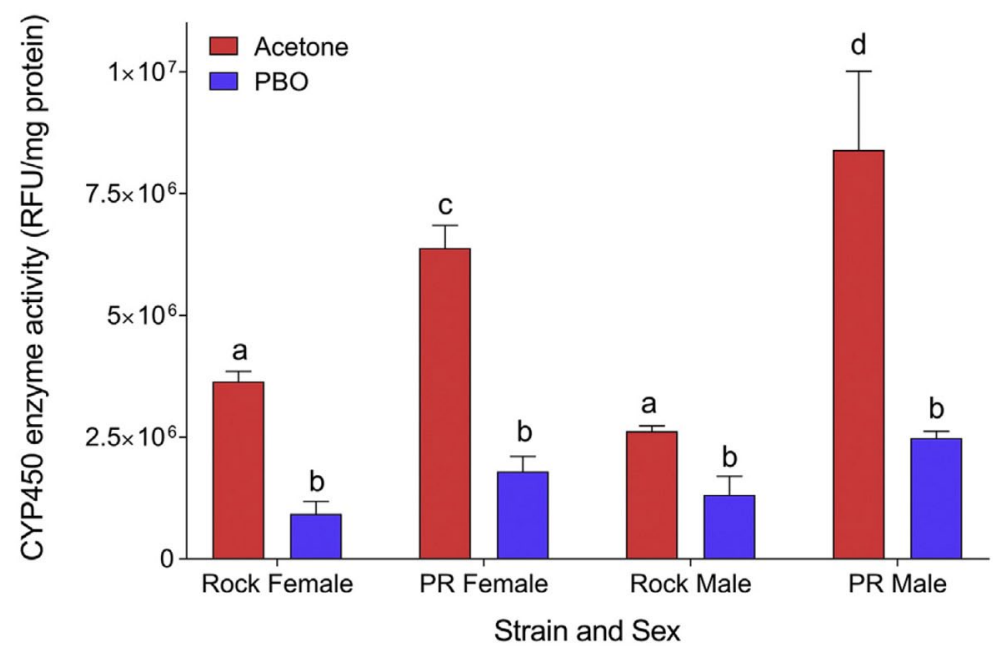

Fig. 1. Bar graphs of the mean cytochrome P450 enzyme activity ( \pm SD) in males and females of the Rockefeller and Puerto Rico strains of the mosquito species $A e-$ des aegypti $4 \mathrm{~h}$ after treatment with acetone or $100 \mathrm{mM}$ PBO. Differences between groups and treatments were determined by a two-way ANOVA, followed by Tukey's multiple comparisons posthoc test. Similar letters over the bars indicate non-significant differences.

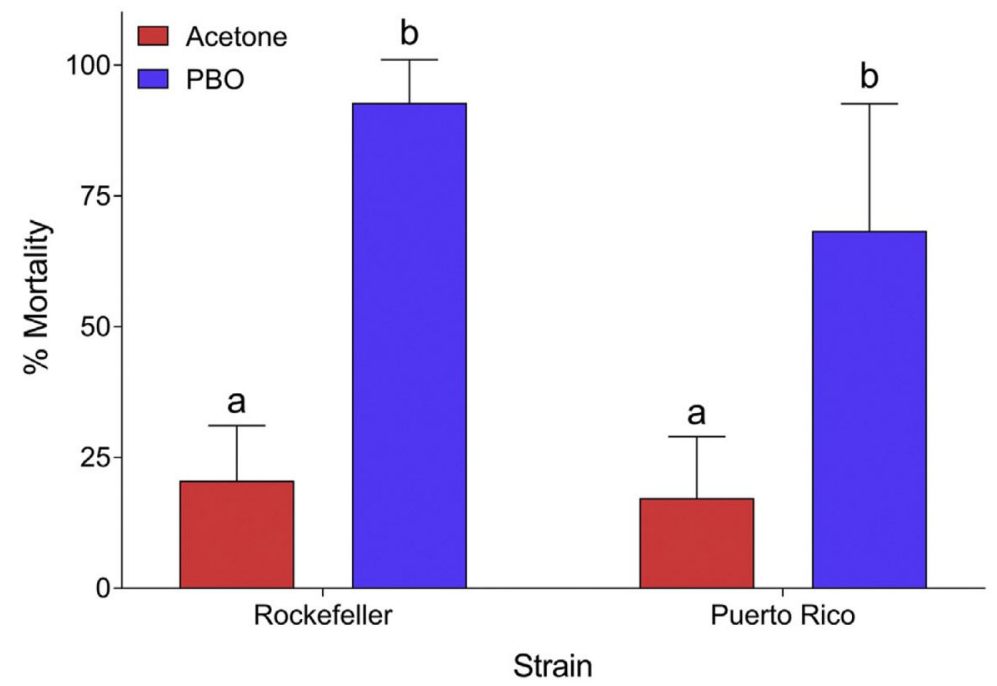

Fig. 2. Bar graphs of mean mortality percentages $( \pm S D)$ in Rockefeller and Puerto Rico strains of the mosquito species Aedes aegypti, males and females of three age groups combined, following exposure to deltamethrin at the appropriate LD25 calculated for each group, with or without PBO pretreatment (100 mM). Differences were determined by a one-way ANOVA and a Sidak's multiple comparisons test. Similar letters over the bars indicate non-significant differences. 


\subsection{Gene expression}

There were significant differences between the PR and Rock strains, between females and males, and/or between the different age groups for all transcripts (Table 3 and Figs. 3 and 4). Strain alone affected the expression of all the CYP9J transcripts, showing an increased expression in PR compared to Rock for all transcripts (fold change>1) except CYP9J26 and 27, for which expression was decreased in PR (fold change $<1$ ). The expression levels of CYP9J10, 19, and 28 were between 2.75- and 133,727- fold higher in PR than in Rock mosquitoes, regardless of sex or age groups (Fig. 3). The transcript CYP9J28 was expressed in Rock at very low levels (abundance close to 0 ), explaining the high fold change value (Table 3). There was a difference in the expression of CYP9J28 based on the age of the mosquitoes, generating a significant difference between sexes between 1 and 5 days old. Males also showed a higher level of expression than females in PR until age 5 to 7 days old. The sex-related expression difference was maintained in all age groups in PR for the gene CYP9J10. The expression of the transcript CYP9J19 decreased in Rock females and males between the older age groups (3 to 5 and 5 to 7 days old), but was not significantly different between ages in the PR strain, explaining the significant interaction of age and strain on the expression of this gene.

CYP9J10

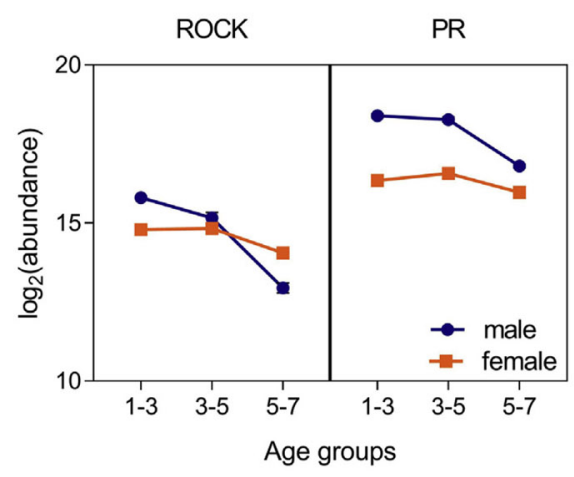

CYP9J19

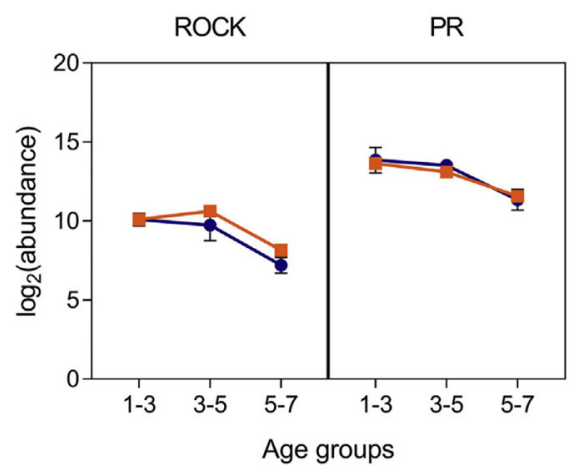

CYP9J28

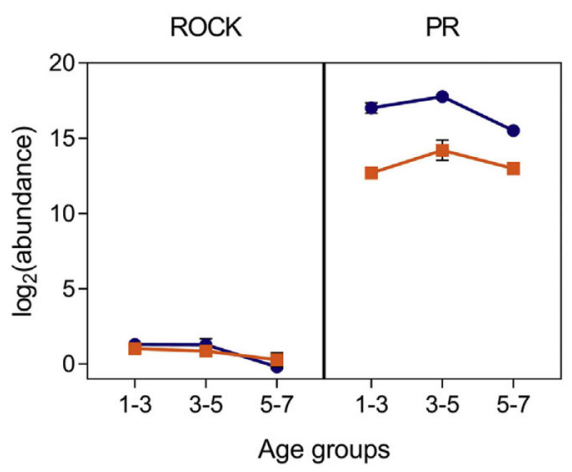

Fig. 3. Expression patterns (mean \pm SD) of three CYP9J transcripts amplified in the qPCR experiment in three age groups of the Rockefeller and Puerto Rico strains of the mosquito species Aedes aegypti, for the two sexes by strain analyzed with the $\mathrm{R}$ package "MCMC.qpcr". Males are represented in dark blue, females in orange. 
Table 3. Significant factors in the expression of the genes tested in the GPCR experiment. The baseline factor levels were age 1 to 3 days old for the age factor, female for the sex factor, and Rockefeller for the strain factor.

\begin{tabular}{|c|c|c|c|}
\hline \multirow{2}{*}{$\frac{\text { Factors affecting expressi }}{\text { Cytochrome P450 9J }}$} & \multicolumn{2}{|c|}{ Fold change Adjusted P-value } & \multirow[t]{2}{*}{ Significance level } \\
\hline & & & \\
\hline \multicolumn{4}{|l|}{ CYP9J10 } \\
\hline Age effect (2) & 0.48 & 0.009 & ** \\
\hline Strain effect & 4.74 & 9.17E-09 & $* * *$ \\
\hline Sex effect & 2.75 & 0.0004 & ** \\
\hline interaction between Age (2) and Sex effects & 0.12 & 9.94E-08 & $* * \star$ \\
\hline interaction between Strain and Sex effects & 2.80 & 0.013 & * \\
\hline \multicolumn{4}{|l|}{ CYP9J 19} \\
\hline Age effect (2) & 0.14 & $9.17 \mathrm{E}-09$ & $\star \star *$ \\
\hline Strain effect & 34.07 & 0 & $* \star \star$ \\
\hline interaction between Age (1) and Strain effects & 0.36 & 0.05 & * \\
\hline \multicolumn{4}{|l|}{ CYP9J24 } \\
\hline Age effect (2) & 0.36 & 0.002 & ** \\
\hline Sex effect & 5.17 & $1.12 \mathrm{E}-06$ & $* * *$ \\
\hline Strain effect & 2.31 & 0.017 & * \\
\hline interaction between Age (1) and Strain effects & 2.97 & 0.029 & * \\
\hline interaction between Age (2) and Sex effects & 0.15 & 4.04E-05 & $* * *$ \\
\hline interaction between Strain and Sex effects & 18.32 & $3.31 \mathrm{E}-10$ & $* * *$ \\
\hline \multicolumn{4}{|l|}{ CYP9J26 } \\
\hline Age effect (1) & 0.38 & 0.001 & ** \\
\hline Age effect (2) & 0.14 & $4.30 \mathrm{E}-11$ & $* \star *$ \\
\hline Sex effect & 6.48 & $1.95 \mathrm{E}-10$ & $* * *$ \\
\hline Strain effect & 0.29 & 5.69E-05 & $* * *$ \\
\hline interaction between Age (1) and Strain effects & 7.15 & $5.64 \mathrm{E}-06$ & $* \star *$ \\
\hline interaction between Age (2) and Sex effects & 0.15 & $5.61 \mathrm{E}-06$ & $* \star *$ \\
\hline interaction between Age (2) and Strain effects & 6.10 & $2.42 \mathrm{E}-05$ & $* \star *$ \\
\hline interaction between Strain and Sex effects & 18.28 & $6.82 \mathrm{E}-12$ & $* * *$ \\
\hline \multicolumn{4}{|l|}{ CYP9J27 } \\
\hline Age effect (2) & 0.39 & 0.006 & ** \\
\hline Sex effect & 4.95 & $5.15 E-07$ & $\star * *$ \\
\hline Strain effect & 0.45 & 0.013 & * \\
\hline interaction between Age (1) and Strain effects & 3.82 & 0.004 & $* *$ \\
\hline interaction between Age (2) and Sex effects & 0.12 & $5.06 \mathrm{E}-06$ & $* * *$ \\
\hline interaction between Age (2) and Strain effects & 2.78 & 0.036 & * \\
\hline interaction between Strain and Sex effects & 13.13 & 9.17E-09 & $* * *$ \\
\hline \multicolumn{4}{|l|}{ CYP9J28 } \\
\hline interaction between Age (1) and Strain effects & 5.22 & 0.025 & * \\
\hline Strain effect & $133,727.33$ & 0 & $* * *$ \\
\hline interaction between Strain and Sex effects & 52.58 & 1.04E-09 & $* * *$ \\
\hline \multicolumn{4}{|l|}{ CYP9J32 } \\
\hline Age effect (2) & 0.33 & 4.10E-05 & $* * *$ \\
\hline Sex effect & 1.83 & 0.035 & * \\
\hline interaction between Age (2) and Sex effects & 0.14 & $2.58 \mathrm{E}-07$ & $* * *$ \\
\hline interaction between Strain and Sex effects & 5.79 & $5.61 \mathrm{E}-06$ & $* * *$ \\
\hline \multicolumn{4}{|l|}{ Housekeeping genes } \\
\hline \multicolumn{4}{|l|}{ Actin } \\
\hline Age effect (2) & 0.26 & $5.15 \mathrm{E}-07$ & $* * *$ \\
\hline Strain effect & 6.17 & $4.72 \mathrm{E}-11$ & $* * *$ \\
\hline interaction between Age (2) and Sex effects & 0.18 & 7.37E-06 & $* * *$ \\
\hline interaction between Age (2) and Strain effects & 2.40 & 0.030 & * \\
\hline \multicolumn{4}{|l|}{ RPS17 } \\
\hline Sex effect & 0.47 & 0.004 & ** \\
\hline interaction between Age (2) and Sex effects & 0.23 & $2.96 \mathrm{E}-05$ & $* * *$ \\
\hline
\end{tabular}

"Age effect (1)" refers to the difference between 1 to 3 days old and 3 to 5 days old, whereas "Age effect (2)" refers to the difference between 1 to 3 days old and 5 to 7 days old.

Significance level codes: "***" Adjusted $P$-value $<.001$; "**" adjusted $P$-value between 0.001 and 0.01 ; "*" adjusted $P$-value between 0.01 and 0.05 . 
CYP9J24

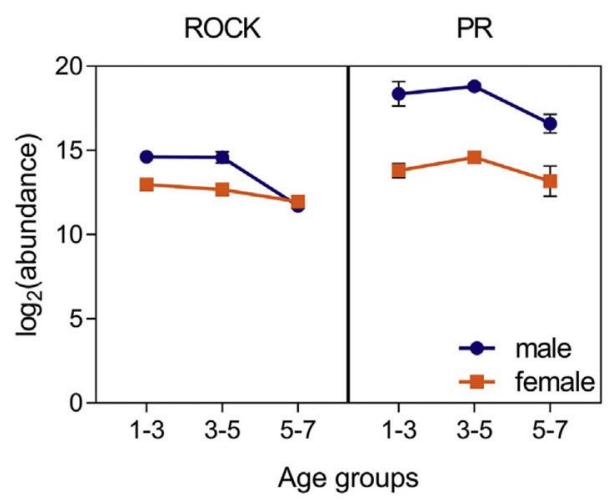

CYP9J27

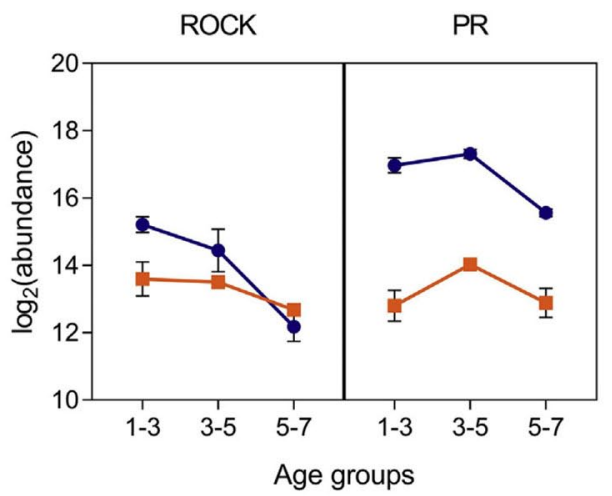

CYP9J26

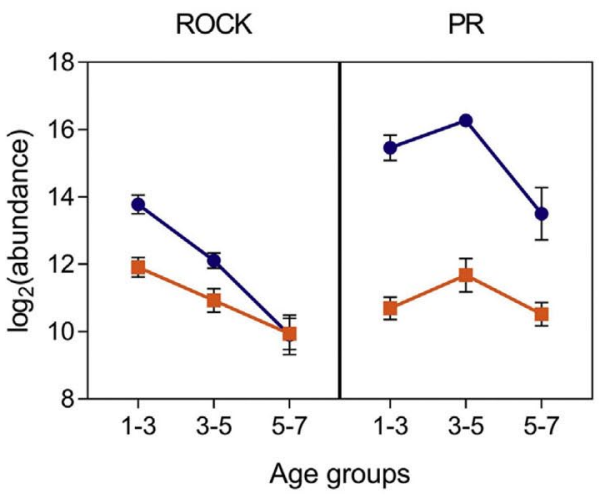

CYP9J32

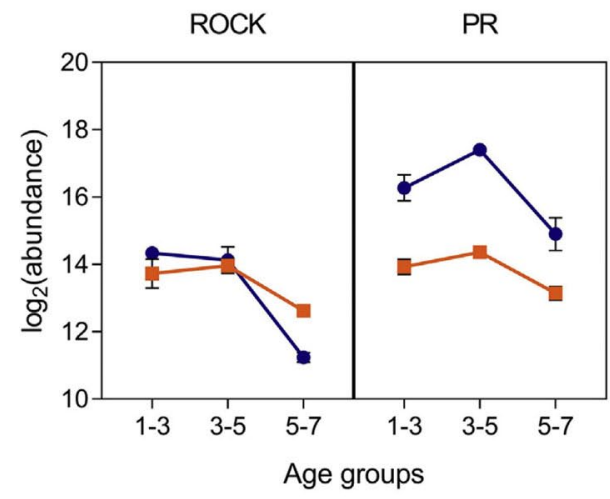

Fig. 4. Expression patterns (mean \pm SD) of four additional CYP9J transcripts amplified in the QPCR experiment in three age groups of the Rockefeller and Puerto Rico strains of the mosquito species Aedes aegypti, for the two sexes by strain analyzed with the R package "MCMC.qpcr". Males are represented in dark blue, females in orange.

For the genes CYP9J24, CYP9J26, CYP9J27, and CYP9J32, the strain difference, although significant (Table 3), was mainly due to PR males exhibiting higher expression levels at all age groups than Rock females and males, as well as higher expression levels than PR females (Fig. 4). The expression of CYP9J10, 24, 26, 27, and 32 was different between age groups with a higher expression level in males than in females, regardless of strain or age. Expression levels of CYP9J10, CYP9J24, CYP9J26, CYP9J27, and CYP9J32 decreased between 1 and 5 and 5 to 7 days old, whereas for the transcript CYP9J26, expression decreased from 3 to 5 days old through 7 days old, particularly in Rock males. 


\section{Discussion}

In this study, the association of age and sex with insecticide toxicity and gene expression in A. aegypti was investigated. More specifically, this study focused on females and males of age groups consisting of 1 to 3 days, 3 to 5 days, and 5 to 7 days post emergence, as they are the main age groups used in other studies (Hougard et al., 2003; Pridgeon et al., 2008; McAllister et al., 2012; Flores et al., 2013; Reid et al., 2014; Ngoagouni et al., 2016; Estep et al., 2017). The comparison of a pyrethroid- resistant to a pyrethroid-susceptible strain gave some insight into the role of certain genes in resistance.

In terms of resistance genes, Hemingway et al. (1989) reported pyrethroid-resistant $A$. aegypti populations to have nonsynonymous mutations in the voltage-gated sodium channels referred to as "knockdown resistance $(k d r)$ mutations" that were potentially selected by prior exposure to DDT. Known kdr mutations include V1016G, S989P, and F1534C in populations from Thailand (Plernsub et al., 2016), V419L in populations from Colombia (Granada et al., 2018), T1520I and F1534C in populations from India (Kushwah et al., 2015), and other populations from Polynesia, Ivory Coast, Vietnam, Indonesia, Thailand, Brazil, and Martinique that also exhibit cross-resistance to DDT conferred by common $k d r$ mutations (Brengues et al., 2003). The PR mosquitoes are a commonly used laboratory strain that is resistant to pyrethroid insecticides and has been shown to carry the $k d r$ mutations V1016I and F1534C (Estep et al., 2017), the most widely reported $k d r$ mutations in this species. Estep et al. (2017) also investigated detoxification mechanisms associated with pyrethroid resistance. They emphasized the abundance of cytochrome P450 genes potentially involved in resistance by comparison to the Orlando susceptible strain. Expression patterns of cytochrome P450 genes were investigated, especially those in the CYP9J family involved in pyrethroid resistance by increased expression in A. aegypti populations from French Guiana, Guadeloupe, and New Caledonia as compared to the susceptible population New Orleans (NO) (Dusfour et al., 2015), and from Grand Cayman and Cuba, also compared to NO (Bariami et al., 2012). CYP9J genes were observed to increase expression in Merida and Isla Mujeres populations (Stevenson et al., 2012), and some of the proteins encoded by these genes were assessed to be able to metabolize deltamethrin, showing the potential of these genes in resistance. Stevenson 
et al. (2012) also proposed to use this increased activity and expression as a resistance monitoring tool in the field.

This study focused on variations in cytochrome P450 activity, the effects of PBO application, and CYP9J gene expression variation between strains, age groups, and sexes that could indicate their involvement in pyrethroid resistance. Based on the results of weight assessment and toxicity bioassays, the analysis showed a difference between the $L_{50} \mathrm{~S}$ of the two strains only, also validating PR as a resistant strain. However, there were no differences in $\mathrm{LD}_{50}$ values between age groups and between sexes. The cytochrome P450 enzyme activity assays showed that constitutively, PR mosquitoes exhibited a higher cytochrome P450 activity than Rock, and that PR males showed the highest activity of all groups. The application of a high concentration of PBO significantly decreased cytochrome P450 activity in PR mosquitoes. Therefore, the increased efficacy of deltamethrin in PR mosquitoes pretreated with $\mathrm{PBO}$ can be attributed to the decrease in cytochrome P450 activity generated by PBO exposure. A variation of this experiment was also performed by Estep et al. (2017), but with a lower concentration of PBO that resulted in only a 2-fold reduction in cytochrome P450 activity, which did not produce a large increase in mortality from permethrin exposure such as the increased mortality observed here with deltamethrin $\left(\mathrm{LD}_{25}\right)$.

Based on both previous studies and the results of this study showing higher cytochrome P450 activity levels in PR mosquitoes, it was hypothesized that the increased activity was due to an increase of CYP9J gene expression. These genes were previously reported to have a potential role in pyrethroid resistance. Since both females and males are resistant to pyrethroids, which was confirmed with deltamethrin $\mathrm{LD}_{50}$ values, the two sexes should exhibit a similar, increased pattern of expression when compared to Rock mosquitoes, in order to increase insecticide detoxification. The quantitative polymerase chain reaction (qPCR) analysis showed that expression of CYP9J10, CYP9J19, and CYP9J28 was increased in the PR strain in both sexes, compared to Rock females and males. These results would corroborate a potential involvement of CYP9J10, CYP9J19, and CYP9J28 in the pyrethroid resistance exhibited by PR mosquitoes. Based on expression patterns of the other CYP9J transcripts tested here, CYP9J24, 26, 27, and 32 may not be directly involved in pyrethroid resistance, due to a similar expression level of PR females, Rock females, and Rock males, 
although it is interesting to note that PR males exhibit an increased expression of these transcripts. The higher expression of all transcripts tested in PR males would match the results of the cytochrome P450 enzyme activity assays showing that constitutively, PR males exhibit a higher cytochrome P450 activity than PR females. These genes may assume different functions that could potentially be linked to resistance. The increased expression in males may suggest a male-specific role for these genes, as shown for the CYP6L1 transcript in the German cockroach (Wen and Scott, 2001), or indicate that these genes are among the estimated 5 to $15 \%$ of cytochrome P450 involved in the reproduction of insects (Scott, 2008); however, this hypothesis remains to be tested.

The relatively high levels of CYP9J transcripts in PR females and males may involve fitness costs if they do confer some type of resistance mechanism or if they are linked to resistance. Fitness costs would need to be determined by comparing emergence time between sexes and between strains, offspring survivability, egg laying potential, as well as other traits such as flight capacity (dispersal) and wingspan to highlight the physiological trade-offs of resistance. Weight is a parameter that is often affected by fitness costs, however, it does not appear to differ significantly between males of the two strains. PR females were significantly heavier than Rock females between 1 and 5 days old, but not beyond 5 days old, suggesting that there may be a cost of resistance on weight beyond a certain age in females, although susceptibility was not increased in the oldest age group in the toxicity assay.

Age was also a significant factor of variation in the transcript expression data. Overall, there was a decrease in expression after day 5 (5 to 7 days old age group) in Rock males, as well as females to a lesser extent, especially for the CYP9J24, 26, 27, and 32 transcripts. If these genes were involved in the metabolism of deltamethrin, it is expected that increased susceptibility would also be observed in mosquitoes older than 5 days old. However, the bioassays did not confirm this hypothesis. Discrepancies were also observed between the results of this study and the results of previously published work focusing on multiple strains of $A$. aegypti. While mosquito resistance testing focuses on females, usually of one restricted age group, this study examined sex and age group differences and provides a more comprehensive picture of expression patterns. CYP9J24 and CYP9J32 have 
been investigated in other studies for their expression levels, the origin of expression changes, and their role in deltamethrin metabolism. However, our results show that, although there is a difference between strains in females of 3 to 5 days old for the transcript CYP9J24, other age groups show that this difference is not significant in younger and older females and the expression of CYP9J32 does not differ between PR and Rock females at any age group. Toxicity bioassays did not support age differences, suggesting that these genes may not be as important in resistance as previously hypothesized.

In conclusion, although the $\mathrm{CDC}$ and $\mathrm{WHO}$ recommend testing female mosquitoes in bioassays, the results of this study show the importance of testing males and females together, since sex was a factor influencing weight, enzyme activity, and gene expression levels. There were no significant differences between age groups when comparing $L D_{50}$ values, which suggests that any age group could be used for this type of bioassay. However, gene expression showed the importance of investigating different age groups to obtain a more comprehensive picture of expression patterns over time. Indeed, these results provided important information regarding the potential involvement of certain genes in pyrethroid resistance.

Acknowledgments - We thank Justine LaViolette and William Noundou for their technical assistance. This research did not receive any specific grant from funding agencies in the public, commercial, or not-for-profit sectors.

\section{References}

Abbott, W.S., 1925. A method of computing the effectiveness of an insecticide. J. Econ. Entomol. 18, 265-267.

Anderson, T.D., Zhu, K.Y., 2004. Synergistic and antagonistic effects of atrazine on the toxicity of organophosphorodithioate and organophosphorothioate insecticides to Chironomus tentans (Diptera: Chironomidae). Pestic. Biochem. Physiol. 80, 54-64.

Bariami, V., Jones, C.M., Poupardin, R., Vontas, J., Ranson, H., 2012. Gene amplification, $A B C$ transporters and cytochrome P450s: unraveling the molecular basis of pyrethroid resistance in the dengue vector, Aedes aegypti. PLoS Negl. Trop. Dis. 6, e1692.

Benjamini, Y., Hochberg, Y., 1995. Controlling the false discovery rate: a practical and powerful approach to multiple testing. J. R. Stat. Soc. Ser. B Methodol. 57, 289-300. 
Brengues, C., Hawkes, N.J., Chandre, F., McCarroll, L., Duchon, S., Guillet, P., Manguin, S., Morgan, J.C., Hemingway, J., 2003. Pyrethroid and DDT crossresistance in Aedes aegypti is correlated with novel mutations in the voltagegated sodium channel gene. Med. Vet. Entomol. 17, 87-94.

Centers for Disease Control and Prevention, 2017. Zika Virus [WWW Document]. CDC. https://www.cdc.gov/zika/vector/range.html (accessed 11.30.17).

Chouaibou, M.S., Chabi, J., Bingham, G.V., Knox, T.B., N'Dri, L., Kesse, N.B., Bonfoh, B., Jamet, H.V.P., 2012. Increase in susceptibility to insecticides with aging of wild Anopheles gambiae mosquitoes from Côte d'Ivoire. BMC Infect. Dis. 12, 214.

Coffey, L.L., Failloux, A.-B., Weaver, S.C., 2014. Chikungunya virus-vector interactions. Viruses 6, 4628-4663.

Desousa, G., Cuany, A., Brun, A., Amichot, M., Rahmani, R., Berge, J.B., 1995. A microfluorometric method for measuring ethoxycoumarin-O-deethylase activity on individual Drosophila melanogaster abdomens: interest for screening resistance in insect populations. Anal. Biochem. 229, 86-91.

Du, Y., Nomura, Y., Zhorov, B.S., Dong, K., 2016. Sodium channel mutations and pyrethroid resistance in Aedes aegypti. Insects 7.

Duffy, M.R., Chen, T.-H., Hancock, W.T., Powers, A.M., Kool, J.L., Lanciotti, R.S., Pretrick, M., Marfel, M., Holzbauer, S., Dubray, C., Guillaumot, L., Griggs, A., Bel, M., Lambert, A.J., Laven, J., Kosoy, O., Panella, A., Biggerstaff, B.J., Fischer, M., Hayes, E.B., 2009. Zika virus outbreak on Yap Island, Federated States of Micronesia. N. Engl. J. Med. 360, 2536-2543.

Dusfour, I., Zorrilla, P., Guidez, A., Issaly, J., Girod, R., Guillaumot, L., Robello, C., Strode, C., 2015. Deltamethrin resistance mechanisms in Aedes aegypti populations from three French overseas territories worldwide. PLoS Negl. Trop. Dis. 9, e0004226.

Dzaki, N., Ramli, K.N., Azlan, A., Ishak, I.H., Azzam, G., 2017. Evaluation of reference genes at different developmental stages for quantitative real-time PCR in Aedes aegypti. Sci. Rep. 7, 43618.

Estep, A.S., Sanscrainte, N.D., Waits, C.M., Louton, J.E., Becnel, J.J., 2017. Resistance status and resistance mechanisms in a strain of Aedes aegypti (Diptera: Culicidae) from Puerto Rico. J. Med. Entomol. 54, 1643-1648.

Flores, A.E., Ponce, G., Silva, B.G., Gutierrez, S.M., Bobadilla, C., Lopez, B., Mercado, R., Black, W.C., 2013. Wide spread cross resistance to pyrethroids in Aedes aegypti (L.) from Veracruz state Mexico. J. Econ. Entomol. 106, 959-969.

Francis, S., Saavedra-Rodriguez, K., Perera, R., Paine, M., Black, W.C., Delgoda, R., 2017. Insecticide resistance to permethrin and malathion and associated mechanisms in Aedes aegypti mosquitoes from St. Andrew Jamaica. PLoS One 12, e0179673.

Georghiou, G.P., Wirth, M., Tran, H., Saume, F., Knudsen, A.B., 1987. Potential for organophosphate resistance in Aedes aegypti (Diptera: Culicidae) in the Caribbean area and neighboring countries. J. Med. Entomol. 24, 290-294.

Granada, Y., Mejía-Jaramillo, A.M., Strode, C., Triana-Chavez, O., 2018. A point mutation $\mathrm{V} 419 \mathrm{~L}$ in the sodium channel gene from natural populations of Aedes aegypti is involved in resistance to $\lambda$-cyhalothrin in Colombia. Insects 9. 
Hemingway, J., Boddington, R.G., Harris, J., Dunbar, S.J., 1989. Mechanisms of insecticide resistance in Aedes aegypti (L.) (Diptera: Culicidae) from Puerto Rico. Bull. Entomol. Res. 79, 123-130.

Hougard, J.-M., Duchon, S., Darriet, F., Zaim, M., Rogier, C., Guillet, P., 2003. Comparative performances, under laboratory conditions, of seven pyrethroid insecticides used for impregnation of mosquito nets. Bull. World Health Organ. 81, 324-333.

Komagata, O., Kasai, S., Tomita, T., 2010. Overexpression of cytochrome P450 genes in pyrethroid-resistant Culex quinquefasciatus. Insect Biochem. Mol. Biol. 40, 146-152.

Kraemer, M.U., Sinka, M.E., Duda, K.A., Mylne, A.Q., Shearer, F.M., Barker, C.M., Moore, C.G., Carvalho, R.G., Coelho, G.E., Bortel, W.V., Hendrickx, G., Schaffner, F., Elyazar, I.R., Teng, H.-J., Brady, O.J., Messina, J.P., Pigott, D.M., Scott, T.W., Smith, D.L., Wint, G.W., Golding, N., Hay, S.I., 2015. The global distribution of the arbovirus vectors Aedes aegypti and Ae. albopictus. elife, vol. 4, e08347.

Kroeger, A., Lenhart, A., Ochoa, M., Villegas, E., Levy, M., Alexander, N., McCall, P.J., 2006. Effective control of dengue vectors with curtains and water container covers treated with insecticide in Mexico and Venezuela: cluster randomised trials. BMJ 332, 1247-1252.

Kushwah, R.B.S., Dykes, C.L., Kapoor, N., Adak, T., Singh, O.P., 2015. Pyrethroidresistance and presence of two knockdown resistance (kdr) mutations, F1534C and a novel mutation T1520I, in Indian Aedes aegypti. PLoS Negl. Trop. Dis. 9, e3332.

Kyle, J.L., Harris, E., 2008. Global spread and persistence of dengue. Annu. Rev. Microbiol. 62, 71-92.

Lines, J.D., Nassor, N.S., 1991. DDT resistance in Anopheles gambiae declines with mosquito age. Med. Vet. Entomol. 5, 261-265.

Lumjuan, N., McCarroll, L., Prapanthadara, L., Hemingway, J., Ranson, H., 2005. Elevated activity of an epsilon class glutathione transferase confers DDT resistance in the dengue vector, Aedes aegypti. Insect Biochem. Mol. Biol. 35, 861-871.

Manjarres-Suarez, A., Olivero-Verbel, J., 2013. Chemical control of Aedes aegypti: a historical perspective. Rev. Costarric. Salud Pública 22, 68-75.

Matz, M.V., Wright, R.M., Scott, J.G., 2013. No control genes required: Bayesian analysis of qRT-PCR data. PLoS One 8, e71448.

McAllister, J.C., Godsey, M.S., Scott, M.L., 2012. Pyrethroid resistance in Aedes aegypti and Aedes albopictus from Port-Au-Prince, Haiti. J. Vector Ecol. 37, 325-332.

Muktar, Y., Tamerat, N., Shewafera, A., 2016. Aedes aegypti as a vector of flavivirus. J. Trop. Dis. Public Health 4.

Musso, D., Nilles, E.J., Cao-Lormeau, V.-M., 2014. Rapid spread of emerging Zika virus in the Pacific area. Clin. Microbiol. Infect. 20, O595-O596.

Ngoagouni, C., Kamgang, B., Brengues, C., Yahouedo, G., Paupy, C., Nakouné, E., Kazanji, M., Chandre, F., 2016. Susceptibility profile and metabolic mechanisms involved in Aedes aegypti and Aedes albopictus resistant to DDT and deltamethrin in the Central African Republic. Parasit. Vectors 9, 599. 
Plernsub, S., Saingamsook, J., Yanola, J., Lumjuan, N., Tippawangkosol, P., Sukontason, K., Walton, C., Somboon, P., 2016. Additive effect of knockdown resistance mutations, S989P, V1016G and F1534C, in a heterozygous genotype conferring pyrethroid resistance in Aedes aegypti in Thailand. Parasit. Vectors 9, 417.

Powers, A.M., Logue, C.H., 2007. Changing patterns of chikungunya virus: reemergence of a zoonotic arbovirus. J. Gen. Virol. 88, 2363-2377.

Pridgeon, J.W., Pereira, R.M., Becnel, J.J., Allan, S.A., Clark, G.G., Linthicum, K.J., 2008. Susceptibility of Aedes aegypti, Culex quinquefasciatus say, and Anopheles quadrimaculatus say to 19 pesticides with different modes of action. J. Med. Entomol. 45, 82-87.

R Core Team, 2013. R: A Language and Environment for Statistical Computing. R Foundation for Statistical Computing, Vienna, Austria.

Rajatileka, S., Burhani, J., Ranson, H., 2011. Mosquito age and susceptibility to insecticides. Trans. R. Soc. Trop. Med. Hyg. 105, 247-253.

Ranasinghe, C., Hobbs, A.A., 1998. Isolation and characterization of two cytochrome P450 CDNA clones for CYP6B6 and CYP6B7 from Helicoverpa armigera (Hubner): possible involvement of CYP6B7 in pyrethroid resistance. Insect Biochem. Mol. Biol. 28, 571-580.

Ranson, H., Burhani, J., Lumjuan, N., Black, W.C.I., 2010. Insecticide resistance in dengue vectors. TroplKA.net J. 1.

Reid, W.R., Thornton, A., Pridgeon, J.W., Becnel, J.J., Tang, F., Estep, A., Clark, G.G., Allan, S., Liu, N., 2014. Transcriptional analysis of four family 4 P450s in a Puerto Rico strain of Aedes aegypti (Diptera: Culicidae) compared with an Orlando strain and their possible functional roles in permethrin resistance. J. Med. Entomol. 51, 605-615.

Riveron, J.M., Irving, H., Ndula, M., Barnes, K.G., Ibrahim, S.S., Paine, M.J.I., Wondji, C.S., 2013. Directionally selected cytochrome P450 alleles are driving the spread of pyrethroid resistance in the major malaria vector Anopheles funestus. Proc. Natl. Acad. Sci. 110, 252-257.

Rodríguez, M.M., Bisset, J., Ruiz, M., Soca, A., 2002. Cross-resistance to pyrethroid and organophosphorus insecticides induced by selection with temephos in Aedes aegypti (Diptera: Culicidae) from Cuba. J. Med. Entomol. 39, 882-888.

Rozen, S., Skaletsky, H., 2000. Primer3 on the WWW for General Users and for Biologist Programmers. In: Misener, S., Krawetz, S.A. (Eds.), Bioinformatics Methods and Protocols. Methods in Molecular Biology ${ }^{\mathrm{TM}}$. 132 Humana Press, Totowa, NJ.

Scott, J.G., 2008. Insect cytochrome P450s: thinking beyond detoxification. In: Liu, N. (Ed.), Recent Advances in Insect Physiology, Toxicology and Molecular Biology. Research Signpost, Kerala, India, pp. 117-124.

Smith, P.K., Krohn, R.I., Hermanson, G.T., Mallia, A.K., Gartner, F.H., Provenzano, M.D., Fujimoto, E.K., Goeke, N.M., Olson, B.J., Klenk, D.C., 1985. Measurement of protein using bicinchoninic acid. Anal. Biochem. 150, 76-85. 
Smith, L.B., Kasai, S., Scott, J.G., 2016. Pyrethroid resistance in Aedes aegypti and Aedes albopictus: important mosquito vectors of human diseases. Pestic. Biochem. Physiol. 133, 1-12.

Stevenson, B.J., Pignatelli, P., Nikou, D., Paine, M.J.I., 2012. Pinpointing P450s associated with pyrethroid metabolism in the dengue vector, Aedes aegypti: developing new tools to combat insecticide resistance. PLoS Negl. Trop. Dis. 6, e1595.

Strode, C., Wondji, C.S., David, J.-P., Hawkes, N.J., Lumjuan, N., Nelson, D.R., Drane, D.R., Karunaratne, S.H.P.P., Hemingway, J., Black, W.C., Ranson, H., 2008. Genomic analysis of detoxification genes in the mosquito Aedes aegypti. Insect Biochem. Mol. Biol. 38, 113-123.

Stumpf, N., Nauen, R., 2001. Cross-resistance, inheritance, and biochemistry of mitochondrial electron transport inhibitor-acaricide resistance in Tetranychus urticae (Acari: Tetranychidae). J. Econ. Entomol. 94, 1577-1583.

Thompson, M., Shotkoski, F., ffrench-Constant, R., 1993. Cloning and sequencing of the cyclodiene insecticide resistance gene from the yellow fever mosquito Aedes aegypti: conservation of the gene and resistance associated mutation with Drosophila. FEBS Lett. 325, 187-190.

Tomita, T., Scott, J.G., 1995. cDNA and deduced protein sequence of CYP6D1: the putative gene for a cytochrome P450 responsible for pyrethroid resistance in house fly. Insect Biochem. Mol. Biol. 25, 275-283.

Tomori, O., 2004. Yellow fever: the recurring plague. Crit. Rev. Clin. Lab. Sci. 41, 391-427.

Ullrich, V., Weber, P., 1972. The O-Dealkylation of 7-ethoxycoumarin by liver microsomes. A direct fluorometric test. Hoppe-Seyler's Z. Für Physiol. Chem. 353, 1171-1177.

Vontas, J., Kioulos, E., Pavlidi, N., Morou, E., della Torre, A., Ranson, H., 2012. Insecticide resistance in the major dengue vectors Aedes albopictus and Aedes aegypti. Pestic. Biochem. Physiol. 104, 126-131.

Wen, Z., Scott, J.G., 2001. Cytochrome P450 CYP6L1 is specifically expressed in the reproductive tissues of adult male German cockroaches, Blattella germanica (L.). Insect Biochem. Mol. Biol. 31, 179-187.

World Health Organization, 1998. Techniques to Detect Insecticide Resistance Mechanisms. (field and laboratory manual, archived).

World Health Organization, 2016. Test Procedures for Insecticide Resistance Monitoring in Malaria Vector Mosquitoes, Second edition. .

Yang, Y., Chen, S., Wu, S., Yue, L., Wu, Y., 2006. Constitutive overexpression of multiple cytochrome P450 genes associated with pyrethroid resistance in Helicoverpa armigera. J. Econ. Entomol. 99, 1784-1789.

Zaim, M., Aitio, A., Nakashima, N., 2000. Safety of pyrethroid-treated mosquito nets. Med. Vet. Entomol. 14, 1-5. 